\title{
HUBUNGAN PENGETAHUAN DAN MOTIVASI BIDAN PRAKTIK SWASTA TERHADAP PELAKSANAAN PIJAT BAYI DI WILAYAH PUSKESMAS KECAMATAN GADING CEMPAKA TAHUN 2011
}

\author{
Shintiya Librayani, Yuniwati \\ Jurusan Kebidanan Poltekkes Kemenkes Bengkulu Jl. Indragiri No.3 Bengkulu \\ Jurusan Kebidanan Poltekkes Kemenkes Bengkulu JI. Indragiri No.3 Bengkulu
}

\begin{abstract}
Incidence of low birth weight in Bengkulu City has increased from 7,86\% in 2009 to $11.50 \%$ in 2010 . One effort to increase the stimulation of growth and development in LBW infants is infant massage.The factors that influence it are knowledge and motivation. The perpose of this study was to determine the relationship of knowledge and motivation of midwives in private practice in the implementasi of inflant massage. This study uses an observational design with a descriptive cross sectional approach, total sampling from 59 BPS. Retrievel of data using the primary data through questionnaires. Analyzed by univariate and bivariate chi squer. The results obtained that almost half of respondents did not perfort inflant massage. There was a significant association between knowledge of midwives in private practice with the implementation of inflant massage $(\mathrm{p}=0.00)$ and there was a significant association between the motivation of BPS with the implementasi of inflant massage $(p=0.009)$. the conclusion from the result of this study is there is a significant relationship between knowledge and motivation of midwives in private practice to the implementation of inflant massage.
\end{abstract}

\begin{abstract}
Abstak : Kejadian BBLR di Kota Bengkulu mengalami peningkatan dari 7,86\% tahun 2009 menjadi $11,50 \%$ tahun 2010. Salah satu upaya untuk meningkatkan stimulasi tumbuh kembang pada bayi BBLR adalah pijat bayi. Faktor yang mempengaruhi diataranya adalah pengetahuan dan motivasi. Tujuan penelitian ini adalah untuk mengetahui hubungan pengetahuan dan motivasi bidan praktik swasta dalam pelaksanaan pijat bayi. Penelitian ini menggunakan desain observasional deskriptif dengan pendekatan cross sectional, diambil secara total sampling sebanyak 59 BPS. Pengambilan data menggunakan data primer melalui kuesioner. Dianalisa secara univariat dan bivariat secara chi square. Hasil penelitian didapat bahwa hampir sebagian responden memiliki pengetahuan yang kurang, sebagian besar memiliki motivasi rendah dan sebagian besar responden tidak melaksanakan pijat bayi. Ada hubungan yang bermakna antara pengetahuan BPS dengan pelaksanaan pijat bayi $(p=0.00)$ dan ada hubungan yang bermakna antara motivasi BPS dengan pelaksanaan pijat bayi $(p=0,009)$. Kesimpulan dari hasil penelitian ini adalah adanya hubungan yang bermakna antara pengetahuan dan motivasi BPS terhadap pelaksanaan pijat bayi.
\end{abstract}

Kata Kunci : Pengetahuan, Motivasi, Pijat bayi, Bidan Praktek Swasta

Tujuan pembangunan kesehatan menuju Indonesia Sehat 2025 adalah meningkatnya kesadaran, kemauan dan kemampuan hidup sehat bagi setiap orang agar memiliki kemampuan untuk menjangkau pelayanan kesehatan yang bermutu, secara adil dan merata serta memiliki derajat kesehatan yang setinggi-tingginya. Jumlah AKB mengalami penurunan, dari 46 per 1000 kelahiran hidup pada tahun 1997,35 per 1000 kelahiran hidup pada tahun 2003 dan menjadi 34 per 1.000 kelahiran hidup pada tahun 2007, SDKI (2007). Kendati terus mengalami penurunan, angka kematian bayi di Indonesia masih jauh lebih tinggi jika dibandingkan dengan negara-negara anggota ASEAN, Susanto (2010). Penyebab utama kematian pada bayi adalah bayi berat lahir rendah (BBLR) 38,94\% dan asfiksia 27,97 \%, Depkes RI (2008).

Kejadian BBLR di kota Bengkulu pada tahun 2010 terjadi kenaikan dibandingkan tahun 2009. Kasus BBLR pada tahun 2009 tercatat $7,86 \%$ kasus dan pada tahun 2010 tercatat $11,50 \%$ kasus (Dinas $\mathrm{Ke}$ sehatan Kota Bengkulu Tahun 2010). Setiap tahun diperkirakan ada 350.000 bayi dengan berat lahir rendah. BBLR telah didefinisikan oleh WHO sebagai bayi lahir dengan berat kurang dari 2500 gram. 
Penyebab BBLR diantaranya adalah asupan gizi ibu kurang pada masa kehamilan, paritas, jarak kelahiran, kadar haemoglobin, pemanfaatan pelayanan antenatal dan lain-lain (Purwanto, 2009).

BBLR yang tidak ditangani dengan baik dapat mengakibatkan hiperbilirubinemia (ikterus). Angka kejadian ikterus fisiologis cukup tinggi. Frekuensi ikterus berkisar 50\% pada bayi cukup bulan dan $75 \%$ pada bayi kurang bulan. Selain ikterus, masalah jangka panjang akibat BBLR adalah gangguan pada pertumbuhan dan perkembangan. lebih dari sepertiga $(36,1 \%)$ anak Indonesia tergolong pendek ketika memasuki usia sekolah. Prevalensi anak pendek ini semakin meningkat dengan bertambahnya usia, baik pada anak laki- laki maupun perempuan (Purwanto, 2009).

Terhadap permasalahan tersebut, perlu upaya penatalaksanaan yang cepat sehingga masalah yang ditimbulkan dari masalah BBLR dapat ditangani. Salah satu usaha yang dapat diberikan dalam membantu mengoptimalkan kondisi bayi agar tetap terpenuhi kebutuhan nutrisinya adalah dengan pemijatan pada bayi atau memberikan stimulasi sentuh (touch). Sentuhan merupakan kebutuhan dasar manusia. Pijat bayi sebagai salah satu bentuk bahasa sentuhan memiliki efek yang positif untuk partumbuhan dan perkembangan bayi. Jika dilakukan secara teratur, maka sentuhan ini akan memberi banyak manfaat untuk bayi (Irawan, 2010). Survey terhadap 6 bidan, ternyata hanya 2 bidan yang telah melaksanakan pijat bayi. Empat bidan yang lain mengaku belum melaksanakan pijat bayi dikarenakan belum mengetahui manfaat pijat bayi secara benar. Selain itu adanya anggapan bahwa pijat bayi bukan merupakan suatu keharusan, sehingga dorongan baik untuk memberikan penyuluhan dan pemijatan tersebut masih kurang.
Berdasarkan data dinas kesehatan kota Bengkulu tahun 2009, puskesmas yang berada di kota Bengkulu tersebar di $8 \mathrm{Ke}$ camatan. Penelitian ini akan dilaksanakan di kecamatan Gading Cempaka dengan alasan memiliki jumlah puskesmas terbanyak yaitu 5 puskesmas dan cakupan kelahiran hidup tertinggi yaitu $27.14 \%$, (data terlampir). Berdasarkan uraian diatas, maka peneliti tertarik untuk meneliti hubungan pengetahuan dan motivasi bidan praktek swasta dalam pelaksanaan pijat bayi di wilayah kerja puskesmas Gading Cempaka Tahun 2011. Tujuan Penelitian ini adalah diketahuinya hubungan pengetahuan dan motivasi bidan praktik swasta dalam pelaksanaan pijat bayi di wilayah puskesmas Gading Cempaka Tahun 2011.

\section{BAHAN DAN CARA KERJA}

Desain penelitian yang digunakan adalah studi observasional deskriptif dengan pendekatan cross sectional. Populasi dalam penelitian ini adalah seluruh bidan praktek swasta di wilayah kerja Puskesmas Kecamatan Gading Cempaka tahun 2011, yaitu sebanyak 59 bidan praktek swasta. Sampel dalam penelitian ini adalah total sampel. Data dianalisis secara univariat dan bivariat, dengan menggunakan uji ChiSquare $\left(\chi^{2}\right)$.

\section{HASIL}

\section{Analisis Univariat}

Analisis univariat pada penelitian ini untuk melihat gambaran distribusi frekuensi pengetahuan dan motivasi bidan praktek swasta sebagai variabel independen dan pelaksanaan pijat bayi sebagai variable dependen. 
Tabel 1. Gambaran Distribusi Frekuensi Pengetahuan, Motivasi dan BPS yang Melaksanakan Pijat Bayi di Wilayah Kerja Puskesmas Kecamatan Gading Cempaka Tahun 2011.

\begin{tabular}{lcc}
\hline \multicolumn{1}{c}{ Variabel } & Frekuensi (N=59) & Persentase (\%) \\
\hline Pengetahuan & 23 & 39 \\
Kurang & 19 & 32,2 \\
Sedang & 17 & 28,8 \\
Baik & & 57,6 \\
Motivasi & 34 & 42,4 \\
Rendah & 25 & 57,6 \\
Tinggi & & 42,4 \\
Pelaksanaan pijat bayi & 34 & \\
Tidak melaksanakan & 25 & \\
Melaksanakan & & \\
\hline
\end{tabular}

Berdasarkan tabel 1 menunjukkan bahwa dari 59 bidan didapatkan hasil bahwa hampir sebagian bidan (39\%) mempunyai pengetahuan yang kurang, sebagian besar $(57,6 \%)$ memiliki motivasi rendah dan sebagian besar bidan $(57,6 \%)$ tidak melaksanakan pijat bayi.
Analisis Bivariat

Analisis bivariat dilakukan untuk mengetahui hubungan pengetahuan dan motivasi bidan praktek swasta terhadap pelaksanaan pijat bayi di wilayah kerja puskesmas kecamatan Gading Cempaka tahun 2011.

Tabel 2. Hubungan Pengetahuan Bidan Praktek Swasta Terhadap Pelaksanaan Pijat Bayi di Wilayah Kerja Puskesmas Kecamatan Gading Cempaka Tahun 2011

\begin{tabular}{|c|c|c|c|c|c|c|c|c|}
\hline \multirow{3}{*}{ Pengetahuan } & \multicolumn{4}{|c|}{ Pelaksanaan pijat bayi } & \multicolumn{2}{|c|}{ Total } & \multirow{3}{*}{$p$} & \multirow{3}{*}{ OR } \\
\hline & \multicolumn{2}{|c|}{ Tidak Melaksanakan } & \multicolumn{2}{|c|}{ Melaksanakan } & \multirow{2}{*}{$\mathbf{F}$} & \multirow{2}{*}{$\%$} & & \\
\hline & $\mathbf{n}$ & $\%$ & $\mathbf{n}$ & $\%$ & & & & \\
\hline Kurang & 19 & 82,6 & 4 & 17,4 & 23 & 100 & & \\
\hline Sedang & 13 & 68,4 & 6 & 31,6 & 19 & 100 & 0,00 & 6,650 \\
\hline Baik & 2 & 11,8 & 15 & 88,2 & 36 & 100 & & \\
\hline
\end{tabular}

Hasil analisis tabel 2 menunjukkan bahwa dari 23 responden yang berpengetahuan kurang, hampir seluruh bidan $(82,6 \%)$ yang tidak melaksanakan pijat bayi dan dari 17 bidan yang berpengetahuan baik, hampir seluruh $(88,2 \%)$ bidan yang melakukan pijat bayi. Berdasarkan uji statistik, didapatkan nilai $p=0,00$, berarti ter- dapat hubungan yang bermakna antara pengetahuan bidan terhadap pelaksanaan pijat bayi, dengan nilai OR 6,650 yang berarti bidan yang memiliki pengetahuan tinggi mempunyai kemungkinan melakukan pijat bayi 7 kali lebih besar dibandingkan bidan yang memiliki pengetahuan rendah.

Tabel 3. Hubungan Motivasi Bidan Praktek Swasta Terhadap Pelaksanaan Pijat Bayi di Wilayah Kerja Puskesmas Kecamatan Gading Cempaka Tahun 2011

\begin{tabular}{|c|c|c|c|c|c|c|c|c|}
\hline \multirow{3}{*}{ Motivasi } & \multicolumn{4}{|c|}{ Pelaksanaan pijat bayi } & \multicolumn{2}{|c|}{ Total } & \multirow{3}{*}{$\begin{array}{c}\text { Nilai } \\
\qquad P\end{array}$} & \multirow{3}{*}{$\mathbf{O R}$} \\
\hline & \multicolumn{2}{|c|}{ Tidak melaksanakan } & \multicolumn{2}{|c|}{ Melaksanakan } & \multirow{2}{*}{$\mathbf{F}$} & \multirow{2}{*}{$\%$} & & \\
\hline & $\mathbf{N}$ & $\%$ & $\mathbf{N}$ & $\%$ & & & & \\
\hline Rendah & 25 & 73,5 & 9 & 26,5 & 34 & 100 & 0009 & \\
\hline Tinggi & 9 & 36 & 16 & 64 & 25 & 100 & 0,009 & 4,938 \\
\hline
\end{tabular}

Berdasarkan tabel 3. terlihat bahwa dari 34 bidan yang memiliki motivasi yang rendah dalam pelaksanaan pijat bayi, sebagian besar $(73,5 \%)$ tidak melaksanakan pijat bayi dan dari 25 bidan yang memiliki motivasi tinggi, sebagian besar $(64 \%)$ melaksanakan pijat bayi. Hasil uji Chi-Square diperoleh hasil $p=0,009$, ini menunjukkan terdapat hubungan yang bermakna antara motivasi bidan terhadap pelaksanaan pijat bayi, dengan nilai OR 4,938 yang berarti bidan yang memiliki motivasi tinggi mempunyai kemungkinan tidak melakukan 
pijat bayi 5 kali lebih besar dibandingkan bidan yang memiliki motivasi rendah.

\section{PEMBAHASAN}

\section{Hubungan Pengetahuan bidan dengan Pe- laksanaan Pijat Bayi}

Hasil penelitian didapatkan bahwa bahwa dari 59 bidan, hampir sebagian bidan $(39 \%)$ mempunyai pengetahuan yang kurang dan dari jumlah tersebut, sebagian besar responden $(82,6 \%)$ tidak melakukan pijat bayi. Hasil uji chi square didapatkan nilai $p=0,00$, yang berarti terdapat hubungan yang bermakna antara pengetahuan bidan praktik swasta dengan pelaksanaan pijat bayi, dengan nilai OR 6,650 yang berarti bidan yang memiliki pengetahuan tinggi mempunyai kemungkinan melakukan pijat bayi 7 kali lebih besar dibandingkan bidan yang memiliki pengetahuan rendah.

Hasil penelitian ini sesuai dengan pendapat Notoatmodjo (2003), bahwa pengetahuan merupakan salah satu faktor yang dapat mempengaruhi perilaku seseorang untuk berbuat atau bertindak positif kearah yang lebih baik, dengan kata lain semakin kurang nya pengetahuan bidan akan mempengaruhi terhadap rendahnya pelaksanaan pijat bayi.

Selain itu, dalam Notoatmodjo (2007) menyatakan bahwa kurangnya pengetahuan tentang suatu hal, membuat seseorang tidak mau tahu dan kurang termotivasi untuk berbuat dan bertindak. Pengetahuan akan memicu pemahaman berfikir seseorang yang selanjutnya menimbulkan motivasi, yang pada akhirnya diwujudkan dalam bentuk perbuatan atau tindakan terhadap suatu pengetahuan yang dihadapi.

Bidan mempunyai wewenang dalam melakukan tindakan Pijat bayi, memberikan informasi dan penyuluhan mengenai manfaat pijat dan pelaksanaannya kepada masyarakat khususnya kepada orang tua, dalam memberikan asuhan sebagai upaya promotif dan preventif sehingga pelaksanaan pijat bayi dapat dilakukan sesuai prosedur (Kemenkes RI, 2007).
Bidan sebagai salah satu pihak yang berpotensi besar memberikan penyuluhan dan pelaksanaan pijat bayi, dapat melakukan suatu kesalahan jika mempunyai tingkat pengetahuan yang rendah dan kesadaran yang tinggi bahwa pijat bayi akan memberikan manfaat yang banyak. Sehingga pemijatan dapat dilakukan secara tepat jika bidan tersebut memiliki pengetahuan tentang pelaksanaan pijat bayi dengan baik. Jika bidan tersebut mempunyai pengetahuan yang kurang, tidak menutup kemungkinan kesalahan dalam melakukan tindakan pijat bayi dapat terjadi. Oleh karena itu pengetahuan bidan sangatlah penting, hal ini dikarenakan tindakan yang dilakukan merupakan salah satu dari respon pengetahuan yang dimiliki (Wismayanti, 2008).

Pengetahuan sangat menentukan masuk atau tidaknya seseorang dalam menyerap dan memahami permasalahan yang diperoleh dari beberapa sumber, dengan pengetahuan yang baik kemampuan untuk menerapkan pengetahuannya dapat terlaksana dengan baik. Pengetahuan yang diterima dapat langsung dinilai baik atau buruk oleh seseorang dan sekaligus sebagai dasar untuk bertindak. Pengetahuan membuat seseorang selalu ingin menggali ilmu yang ada sehingga membuat dirinya merasa harus terus mempelajarinya. Baiknya pengetahuan seseorang akan mempermudahkan dirinya untuk memahami arti penting kesehatan, proses berfikir positif timbul sehingga seseorang termotivasi untuk selalu bertindak memperbaiki dirinya melalui pelayanan kesehatan (Notoatmodjo, 2007).

Hal penelitian ini juga sejalan dengan penelitian yang dilakukan oleh Smart (2008) menyatakan bahwa pengetahuan sangat mempengaruhi perilaku, semakin baik pengetahuan perawat terhadap pijat bayi maka semakin baik perilaku atau tindakannya dalam melaksanakan pemijatan pada bayi. Selain itu, penelitian yang dilakukan oleh Baskoro (2008), menyatakan bahwa responden yang berpengetahuan sedang akan diikuti dengan tindakan 
yang cukup, begitu pula dengan reponden yang memiliki pengetahuan kurang maka akan diikuti dengan tindakan yang kurang pula.

Berdasarkan hasil observasi dan penelitian ini didapatkan dari 23 responden yang memiliki pengetahuan kurang, sebagian besar $(82,6 \%)$ bidan tidak melaksanakan pijat bayi. Namun dari 17 bidan berpengetahuan baik, masih ada bidan yang tidak melaksanakan pijat bayi $(11,8 \%)$. Hal ini dapat disebabkan banyak faktor yang mungkin mempengaruhi seseorang dalam berperilaku. Seperti yang dikemukakan kembali oleh Notoadmojo (2007) bahwa Faktor yang berpengaruh dalam determinan perilaku manusia antara lain pengalaman, keyakinan, fasilitas, sosial budaya, pengetahuan, persepsi, sikap, keinginan, kehendak, motivasi dan niat.

\section{Hubungan Motivasi Bidan dengan Pe- laksanaan Pijat Bayi}

Hasil penelitian menunjukkan bahwa sebagian besar responden memiliki motivasi rendah $(57,6 \%)$, sebagian besar (73, $5 \%)$ tidak melaksanakan pijat bayi. Hasil uji Chi square diperoleh nilai $p=0,009$ yang berarti terdapat hubungan yang bermakna antara motivasi bidan praktik swasta dengan pelaksanaan pijat, dengan nilai OR 4,938 yang berarti bidan yang memiliki motivasi tinggi mempunyai kemungkinan melakukan pijat bayi 5 kali lebih besar dibandingkan bidan yang memiliki motivasi rendah.

Hasil ini sesuai dengan pendapat Notoatdmojo (2007) bahwa motivasi adalah pemberian daya penggerak terdapat pada diri seseorang individu yang mendorongnya untuk melakukan perbuatan (perilaku) dan merupakan faktor yang berpengaruh dalam kinerja (perilaku) seorang karyawan.

Motivasi merupakan suatu proses psikologis yang mencerminkan antara interaksi sikap, persepsi dan kepribadian yang ada pada diri seseorang. Berdasarkan observasi dan penelitian yang ada, semakin tinggi motivasi seseorang maka semakin tinggi keinginan mencapai tujuan yang ingin dicapai. Sejalan dengan pendapat Notoadmojo (2007) yang menyatakan bahwa salah satu faktor yang mempengaruhi seseorang dalam pekerjaannya yaitu faktor penyebab kepuasan (satisfierr) atu motivasional. Faktor ini menyangkut kebutuhan psikologis seseorang yang meliputi serangkaian kondisi intrinsic. Apabila kepuasan kerja dicapai , akan menghasilkan kinerja yang tinggi. Factor tersebut mencakup prestasi (achievement), penghargaan (recognition), tanggung jawab (responsibility), kesempatan untuk maju (possibility of growth) dan pekerjaan itu sendiri (work)

Berdasarkan hasil observasi dan penelitian ini didapatkan dari 34 responden yang memiliki motivasi rendah, sebagian besar bidan $(67,6 \%)$ tidak melaksanakan pijat bayi. Namun dari 25 bidan yang memiliki motivasi tinggi, masih ada bidan yang tidak melaksanakan pijat bayi yaitu sebesar (36\%). Hal ini sesuai dengan pendapat Notoatdmojo (2007) bahwa faktor yang berpengaruh dalam determinan perilaku manusia antara lain pengalaman, keyakinan, fasilitas, sosial budaya, pengetahuan, persepsi, sikap, keinginan, kehendak, motivasi dan niat.

\section{KESIMPULAN}

Berdasarkan hasil penelitian hubungan pengetahuan dan motivasi bidan praktik swasta terhadap pelaksanaan pijat bayi wilayah Puskesmas kecamatan Gading Cempaka pada tahun 2011 maka dapat ditarik kesimpulan sebagai berikut : Penelitian ini menemukan bahwa Hampir sebagian responden memiliki pengetahuan kurang, sebagian besar responden memiliki motivasi rendah dan sebagian besar responden tidak melaksanakan pijat pada bayi. Ada hubungan bermakna antara pengetahuan dan motivasi terhadap pelaksanaan pijat bayi.

Saran bagi Pelayanan Kesehatan diharapkan dapat menjadikan sumber informasi bagi petugas kesehatan, terutama bagi organisasi profesi (IBI) agar dapat memberikan informasi dan pengalaman kepada 
para petugas kesehatan melalui seminar agar kemudian dapat memberikan penyulu- han mengenai pijat bayi khususnya kepada orang tua sesuai dengan prosedur.

\section{DAFTAR KEPUSTAKAAN}

Ajunk. 2009. Filosofi Pengetahuan. Diakses tanggal 13 februari 2011.

Alim, M B. 2010. Motivasi dalam pendidikan. Diperoleh dari http://www.psikologi zone.com/motivasi-dalam-pendidikan. Diakses tanggal 06 februari 2011.

Anwar, Y. 2010. Ikterus Neonatorum. Diperoleh dari http://yulianyanwar.blogspot. com/2010/11/ikterus-neonatorum.html.

Diakses tanggal 13 Januari 2011.

Arif W, H. 2008. Pengetahuan. Diperoleh dari http://ajangberkarya.wordpress. com/2008/06/07/konsep-pengetahuan. Diakses tanggal 24 januari 2011.

Arikunto, S. 1996. Dasar - Dasar Evaluasi Pendidikan. Jakarta: Bumi Aksara. 2006. Prosuder Penelitian Suatu Pendekatan Praktik Edisi Revisi VI. Jakarta: Rineka Cipta.

Asri, S, dkk. 2009. Pengaruh Pijat Bayi Terhadap Kenyamanan Tidur Bayi di Kelurahan Selagalas Kecamatan Sandubaya Kotamadya Mataram. Jurnal Kesehatan Prima, 3: 451 - 6.

Baskoro, A. 2008. Dampak pengetahuan dan persepsi terhadap sikap mahasiswa terhadap HIV/AIDS. Diperoleh dari http://baskoro1.blogspot.com/2008/03/dampak -pengetahuan-dan-perspsi.html. diakses tanggal 20 Juni 2011.

Budiarto, E. 2002. Biostatistika Untuk Kedokteran \& Kesehatan Masyarakat. Jakarta: EGC.

Departemen Kesehatan RI. 2009. Rencana Pembangunan Jangka Panjang Bidang Kesehatan 2005-2025. Diakses tanggal 11 Januari 2011.

2007. Buku Pedoman

Karya Tulis Ilmiah.

Dowshen, dkk. 2002. Panduan kesehatan balita: petunujuk lengkap untuk orang tua dari masa kehamilan sampai usia anak 5 tahun. Jakarta: Raja Grafindo Persada.

Handayani, T, dkk. 2009. Hubungan Motivasi Ibu Dengan Pemberian Asi Eksklusif Pada Bayi Umur 6 Bulan Sampai 2 Tahun. Jurnal Penelitian Poltekkes, 4: 296 - 1.

Hendrik, dkk. 2009. Pengaruh Pijat Bayi Terhadap Penambahan Berat Badan Dan Panjang Badan Bayi Usia 0 - 4 Bulan di Rumah Bersalin Fatimah Makassar. Media Kesehatan Politeknik kesehatan Makassar,

Irawan, I D. 2010. Pemijatan optimalkan tumbuh kembang bayi. Diperoleh dari http://harianjoglosemar.com/berita. Diakses tanggal Tanggal 09 Januari 2011.

Lisender. 2009. Prestasi Didapat Lewat Pengorbanan. Diperoleh dari http://sman6 pontianak.sch.id. Diakses tanggal 25 Februari 2011.

Mulyati, S, dkk. 2009. Pengaruh Pijat Bayi Terhadap Kuantitas Tidur Bayi Umur 5-6 Bulan Di Wilayah Kerja Puskesmas Jalan Gedang Kota Bengkulu Tahun 2009. Media Kesehatan Politeknik kesehatan Bengkulu.

Notoatmodjo, S. 2005. Metodologi Penelitian. Jakarta: Rineka cipta. 2005. Promosi kesehatan teori dan aplikasi. Jakarta: Rineka cipta. 2007. Promosi kesehatan \& ilmu perilaku. Jakarta: Rineka cipta.

Nursalam. 2003. Konsep \& penerapan metodologi penelitian ilmu keperwatan. Jakarta : Salemba medika.

Purwanto, E R. 2009. Masalah Bblr Di Indonesia. Diakses tanggal 13 januari 2011.

Riduwan. 2008. Skala pengukuran variabel variabel penelitian. Jawa Barat: IKAPI.

Riwidikdo, H. 2010. Statistik Untuk Penelitian Kesehatan. Yogyakarta: Pustaka Rihima.

Roesli, U. 2001. Pedoman pijat bayi (edisi revisi). Jakarta : Trubus Agriwidya.

2001. Pedoman pijat bayi premature \& bayi usia $0-3$ bulan. Jakarta: Trubus Agriwidya.

Sastroasmoro, S. 2002. Dasar - Dasar Metodologi Penelitian Klinis. Jakarta: Sagung Seto.

Smart, S. 2008. Hubungan pengetahuan tentang pijat bayi dengan sikap perawat dalam tindakan pijat bayi. Diperoleh dari http://skripsistikes.wordpress. com/2009/05/08/kpiii117. Diakses tanggal 23 Februari 2011.

Susanto, C E. 2010. Angka Kematian Bayi Masih tinggi. Diperoleh dari http:// bataviase .co.id/node/110111. Diakses tanggal 13 februari 2011.

Widayatun, T. R. 1999. Ilmu Prilaku. Jakarta: Agung Seto.

Wiknjosastro, H. 2005. Ilmu Kebidanan. Jakarta: yayasan Bina Pustaka Sarwono Prawirohardjo.

Wismayanti, L. 2008. Pengaruh Penyuluhan Tentang Pijat Bayi Terhadap Prilaku Ibu dalam Melakukan Pijat Bayi Secara Mandiri Di Posyandu Jembowati Desa Purwomartini Kec. Kelasan Kab. Sleman Yogyakarta. Diakses tanggal 23 februari 2011. 